\title{
Myelin Impairs CNS Remyelination by Inhibiting Oligodendrocyte Precursor Cell Differentiation
}

\author{
Mark R. Kotter, Wen-Wu Li, Chao Zhao, and Robin J. M. Franklin \\ Cambridge Centre for Brain Repair and Department of Veterinary Medicine, University of Cambridge, Cambridge CB3 0ES, United Kingdom
}

\begin{abstract}
Demyelination in the adult CNS can be followed by extensive repair. However, in multiple sclerosis, the differentiation of oligodendrocyte lineage cells present in demyelinated lesions is often inhibited by unknown factors. In this study, we test whether myelin debris, a feature of demyelinated lesions and an in vitro inhibitor of oligodendrocyte precursor differentiation, affects remyelination efficiency. Focal demyelinating lesions were created in the adult rat brainstem, and the naturally generated myelin debris was augmented by the addition of purified myelin. After quantification of myelin basic protein mRNA expression from lesion material obtained by laser capture microdissection and supported by histological data, we found a significant impairment of remyelination, attributable to an arrest of the differentiation and not the recruitment of oligodendrocyte precursor cells. These data identify myelin as an inhibitor of remyelination as well as its well documented inhibition of axon regeneration.
\end{abstract}

Key words: regeneration; remyelination; oligodendrocyte precursor cell; myelin; differentiation; macrophage

\section{Introduction}

The adult CNS contains a precursor cell population that responds to demyelination by undergoing rapid proliferation, migration, and differentiation into new oligodendrocytes (Horner et al., 2000; Franklin, 2002). This regenerative process is called remyelination and can occur in the demyelinating disease multiple sclerosis (Prineas and Connell, 1979). However, for unknown reasons, the process may become arrested at the differentiation/ maturation phase, leaving lesions containing oligodendrocyte lineage cells but chronically demyelinated and vulnerable to progressive axonal degeneration (Wolswijk, 1998; Chang et al., 2000, 2002). An understanding of the regulation of oligodendrocyte precursor cell (OPC) differentiation during remyelination is therefore critical to understand the reasons for its failure and strategies by which it might be enhanced therapeutically.

Developmental studies have provided valuable insight into the process of OPC differentiation. However, regeneration in the adult may differ considerably from processes occurring during development (Arnett et al., 2004). For example, a distinctive feature of the environment for remyelination is the presence of abundant myelin debris generated during demyelination. In vitro studies indicate that myelin can selectively arrest OPC differentiation and suggest that the efficient removal of myelin debris is a necessary prerequisite before new myelin sheaths can be formed after demyelination (Robinson and Miller, 1999). This hypothesis is supported by pathological studies linking efficient clearance

Received June 24, 2005; revised Nov. 7, 2005; accepted Nov. 14, 2005.

This work was supported by the United Kingdom Multiple Sclerosis Society, the Commission of the European Communities (QLK6-CT-2000-00179), and the Van Geest Foundation. M.R.K. was supported by the Austrian Science Fund and the Raymond and Beverly Sackler Foundation.

Correspondence should be addressed to Prof. Robin J. M. Franklin, Department of Veterinary Medicine, University of Cambridge, Madingley Road, Cambridge CB3 0ES, UK. E-mail: rif1000@cam.ac.uk.

DOI:10.1523/JNEUROSCI.2615-05.2006

Copyright $\odot 2006$ Society for Neuroscience $\quad$ 0270-6474/06/260328-05\$15.00/0 of myelin debris to efficient remyelination and experimental studies in which delayed phagocytosis of myelin debris is associated with a simultaneous delay of OPC differentiation (Kotter et al., 2005). However, it is not known whether the clearance of myelin debris per se is beneficial, or whether it simply reflects appropriate activation of macrophages that contribute to repair by other mechanisms such as expression of key signaling molecules. To resolve this issue, we created toxin-induced demyelinating lesions in the adult rat brain stem, supplemented the myelin debris load within the lesion by injecting purified myelin, and compared the efficiency of remyelination with lesions injected with a non-CNS cell debris preparation of liver cell membranes or PBS.

\section{Materials and Methods}

Surgical procedures. All experiments were performed in compliance with United Kingdom Home Office regulations and institutional guidelines. Bilateral focal areas of demyelination were created in the caudal cerebellar peduncle (CCP) of young adult female Sprague Dawley rats (200-240 g) by stereotactic injection of $4 \mu \mathrm{l}$ of $0.01 \%$ ethidium bromide, as described previously (Woodruff and Franklin, 1999) ( $\alpha=8.2^{\circ}$; anteroposterior, $-11.4 \mathrm{~mm}$; lateral, $\pm 2.6 \mathrm{~mm}$; ventroposterior, $-7.07 \mathrm{~mm})$. General anesthesia was induced using $4 \%$ isofluorane in oxygen and maintained by a continuous delivery of $4 \%$ isofluorane-oxygen mixture or intravenous infusion of propofol (Rapinovet; Mallinckrodt, Uxbridge, UK). Diazepam (1.7 mg/kg, i.p.; C.P. Pharmaceuticals, Wrexham, UK) was administered to facilitate anesthesia, buprenorphine hydrochloride ( $0.03 \mathrm{mg} / \mathrm{kg}$, i.m.; Vetergesic; Animalcare, Hull, UK) provided analgesia, and warm sterile saline $(1 \mathrm{ml} / 100$ g, i.p.) maintained normal hydration during the surgical procedure and recovery. Three days later, the procedure was repeated, and $4 \mu \mathrm{l}$ of myelin, liver membranes, or PBS was injected into the same area. After 9, 14, and $28 \mathrm{~d}$, animals were killed, and the tissue was treated according to the requirements of the subsequent analysis.

Purification of myelin and liver membrane fractions. Myelin was isolated using a discontinuous sucrose gradient (Norton and Poduslo, 1973). In 
brief, sucrose was dissolved in sterile-filtered $2.5 \mathrm{~mm}$ Tris/ $\mathrm{HCl}, \mathrm{pH} 7.0$, to form $0.25,0.32$, and $0.88 \mathrm{~m}$ solutions. The brains of two young Sprague Dawley rats were homogenized in ice-cold $0.32 \mathrm{~m}$ sucrose using a mechanical blender (Ultra-Turrax; IKA, Staufen, Germany). The homogenate was diluted to a final $0.25 \mathrm{M}$ sucrose solution and pelleted in an ultra-centrifuge $\left(55,000 \times g, 4^{\circ} \mathrm{C}, 10 \mathrm{~min}\right)$. The pellet was resuspended in $0.88 \mathrm{M}$ sucrose solution and carefully overlaid with $0.25 \mathrm{M}$ sucrose. After ultra-centrifugation $\left(100,000 \times g, 4^{\circ} \mathrm{C}, 1 \mathrm{~h}\right)$, the interface was collected and washed in $30 \mathrm{ml}$ of distilled $\mathrm{H}_{2} \mathrm{O}\left(\mathrm{dH}_{2} \mathrm{O}\right)\left(55,000 \times \mathrm{g}, 4^{\circ} \mathrm{C}, 10 \mathrm{~min}\right)$. The pellet was resuspended in $\mathrm{dH}_{2} \mathrm{O}$ and incubated for $60 \mathrm{~min}$ on ice for osmotic disintegration. After centrifugation $\left(55,000 \times \mathrm{g}, 4^{\circ} \mathrm{C}, 10 \mathrm{~min}\right)$, the flotation step was repeated. The interface was collected and washed twice in $\mathrm{dH}_{2} \mathrm{O}\left(55,000 \times \mathrm{g}, 4^{\circ} \mathrm{C}, 10 \mathrm{~min}\right)$, and the pellet was finally resuspended in an equal volume of $1 \times$ PBS.

Liver membrane fractions were isolated after homogenization of the tissue in $0.85 \mathrm{M}$ sucrose. The homogenate was layered onto a $1.23 \mathrm{M}$ sucrose solution. After centrifugation $\left(100,000 \times g, 4^{\circ} \mathrm{C}, 1 \mathrm{~h}\right)$, the interface was collected and washed in $\mathrm{dH}_{2} \mathrm{O}\left(55,000 \times g, 4^{\circ} \mathrm{C}, 10 \mathrm{~min}\right)$. Finally, the pellet was resuspended in an equal volume of $1 \times$ PBS. The protein content of both myelin and liver membrane preparations was measured by Bradford colorimetric analysis. Both preparations were injected into lesions with the same protein content of $3.5 \mathrm{mg} / \mathrm{ml}$.

Sample preparation for laser-capture microdissection. For RNA analysis, the extracted brain area containing the lesions (a total of 22 lesions from 16 animals; 5 lesions per treatment group apart from PBS controls at day 14) was snap-frozen in n-pentane at $-23^{\circ} \mathrm{C}$ and stored at $-80^{\circ} \mathrm{C}$ until further use. After OCT embedding, $30 \mu \mathrm{m}$ cryostat sections were cut and thaw mounted onto membrane slides (P.A.L.M. Microlaser Systems, Bernried, Germany). Dried slides were immersed in $70 \%$ ethanol (EtOH) for $3 \mathrm{~min}$, stained with toluidine blue $(0.5 \%$ in $50 \% \mathrm{EtOH})$, rinsed in molecular biology grade $\mathrm{H}_{2} \mathrm{O}$ (Sigma, St. Louis, $\mathrm{MO}$ ), and dehydrated in graded EtOHs (70-100\%) including a final xylene step (30 s each). Once the sections were dry, the slides were placed on the LCM system (P.A.L.M. Microlaser Systems). Eight central lesion areas were outlined, cut, and captured into a single Eppendorf tube containing lysis buffer (P.A.L.M. Microlaser Systems) (see Fig. 1). The samples were incubated at $42^{\circ} \mathrm{C}$ for $30 \mathrm{~min}$ and kept at $-80^{\circ} \mathrm{C}$ until further use. RNA extractions were done using a commercially available kit (P.A.L.M. Microlaser Systems), and the quality was assessed by gel electrophoresis (Picochip, Agilent 2100 Bioanalyser; Agilent, Palo Alto, CA). Only samples with good RNA quality were included in the additional analysis (PBS: two lesions from two animals at $14 \mathrm{~d}$, five lesions from three animals at $28 \mathrm{~d}$; myelin: five lesions from three animals at $14 \mathrm{~d}$, four lesions from five animals at $28 \mathrm{~d}$; liver membrane: five lesions from three animals at $28 \mathrm{~d}$; all lesions were treated separately).

Quantitative assessment of remyelination by quantitative PCR for myelin basic protein and $\beta 2$-microglobulin. Quantitative PCR (qPCR) for myelin basic protein (MBP) and $\beta 2$-microglobulin $(\beta 2-\mathrm{MG})$ was performed on an Applied Biosystems (Foster City, CA) 7500 Real-Time PCR System (20 $\mu \mathrm{l}$ reaction volume; $2 \mathrm{~min}$ at $50^{\circ} \mathrm{C}, 15 \mathrm{~min}$ at $95^{\circ} \mathrm{C}, 15 \mathrm{~s}$ and $95^{\circ} \mathrm{C}$, and $1 \mathrm{~min}$ at $60^{\circ} \mathrm{C}$ for 40 cycles). MBP and $\beta 2-\mathrm{MG}$ mRNA were detected using commercially available assays (Applied Biosystems; Rn 00566745_M1 and Rn 00560865_M1). All reactions were performed in triplicate, and the average mean was used to calculate $-\Delta$ CT values, which were finally converted into $\mathrm{MBP} / \beta 2-\mathrm{MB}$ ratios $\left(r=2^{-\Delta \mathrm{CT}}\right)$.

Histological analysis of remyelination. Three animals per group (PBS injected and myelin injected) were perfused with $4 \%$ phosphate-buffered glutaraldehyde at $28 \mathrm{~d}$ after lesion induction, and the brains were postfixed overnight. Tissue blocks encompassing the CCP were cut, and the blocks were processed through osmium tetroxide, dehydrated, and embedded in TAAB resin (TAAB Laboratories, Aldermaston, UK). Semithin sections $(1 \mu \mathrm{m})$ were cut and stained with alkaline toluidine blue. Selected blocks were trimmed, and ultrathin sections cut for electron microscopy.

Detection of OPC and macrophage mRNAs by in situ hybridization. Probes were prepared for platelet-derived growth factor receptor- $\alpha$ (PDGF-R $\alpha$ ) (Sim et al., 2002b), Nkx2.2 (Fancy et al., 2004), and scavenger receptor-B (SR-B) (Zhao et al., 2005) as described previously. Positive $(+)$ cells in CCP lesions (PBS: 10 lesions from five animals; myelin:
10 lesions from five animals) were analyzed at $8 \mathrm{~d}$ after lesion induction. Animals were perfused with $4 \%$ paraformaldehyde in PBS, and $15 \mu \mathrm{m}$ tissue sections were prepared for in situ hybridization as described previously (Fruttiger et al., 1999; Sim et al., 2002b). After in situ hybridization, RNA hybrids were visualized by a standard technique. Lesions were identified on digital images of solochrome cyanine-stained sections, and the lesion area was determined using a public domain program (Image J 1.29; free download at http://rsb.info.nih.gov/ij/). The same program was used to determine the number of positive cells within the lesions on digitized adjacent sections. Densities were calculated as the ratio of cell numbers per lesion area.

Statistical analysis. Statistical significant differences for relative MBP expression values were confirmed by the Kruskal-Wallis test, and $p$ values between the groups were calculated using the Mann-Whitney $U$ test. Equally, OPC density was compared by calculating a Mann-Whitney $U$ test. All calculations were performed using Prism software (Graph Pad, San Diego, CA).

\section{Results}

\section{Increasing the myelin load within areas of demyelination results in an inhibition of remyelination}

Focal areas of demyelination were created in the brain-stem white matter of adult rats by stereotactic injection of $4 \mu \mathrm{l}$ of $0.01 \%$ ethidium bromide (Fig. 1 $a, b$ ). This procedure results in oligodendrocyte death and consequent generation of myelin debris within the lesion. Three days later, the myelin debris load within the lesion was increased by a second injection of purified myelin using the same stereotactic coordinates. Control animals received an injection of liver cell membrane preparations with the same protein content $(3.5 \mathrm{mg} / \mathrm{ml})$ or PBS (Fig. $1 c, d)$. The animals were left to survive for 14 and $28 \mathrm{~d}$, at which time remyelination in this model is complete (Woodruff and Franklin, 1999; Sim et al., 2000). To quantify remyelination, we determined the ratio of $\mathrm{MBP}$, a major component of myelin sheaths, relative to $\beta 2-\mathrm{MG}$ mRNA expression by RT-qPCR on total RNA extracted from laser-capture microdissected lesion tissue (Fig. 1e-h). At $14 \mathrm{~d}$, relative MBP mRNA levels were low in both myelin-treated and control animals. At $28 \mathrm{~d}$, PBS-injected animals displayed a significant increase in relative MBP expression (Fig. $2 a$ ). In striking contrast, the $\mathrm{MBP} / \beta 2-\mathrm{MG}$ ratio in myelin-treated animals failed to increase (Mann-Whitney $U$ test, $p=0.0079$; Kruskal-Wallis test, $p=0.0009)$. Animals injected with purified liver membranes displayed higher relative MBP mRNA levels $(p=0.0079)$ than myelin-treated animals but failed to reach the MBP mRNA expression of PBS controls ( $p=0.0079$ ). The difference in relative MBP mRNA levels between the treatment and control groups was confirmed by light-microscopic examination of resin sections; whereas remyelination was extensive in the PBS-treated group, most of the axons remained demyelinated and separated by pale homogenously staining myelin debris in the myelin-treated group (Fig. 2b,c). Although most of the axons remained demyelinated, the numbers of axons within the lesion was high, and there was no indication of a substantially greater axonal loss in the myelin-treated group that might account for the decreased MBP mRNA levels.

\section{Neither OPC nor macrophage recruitment is affected by the presence of increased myelin load}

Remyelination of ethidium bromide-induced demyelination is mediated by OPCs that are recruited into the area of demyelination and that subsequently differentiate into remyelinating oligodendrocytes (Sim et al., 2002b; Fancy et al., 2004). Because myelin substrates inhibit OPC differentiation in vitro (Robinson and Miller, 1999), we hypothesized that the impaired remyelination 

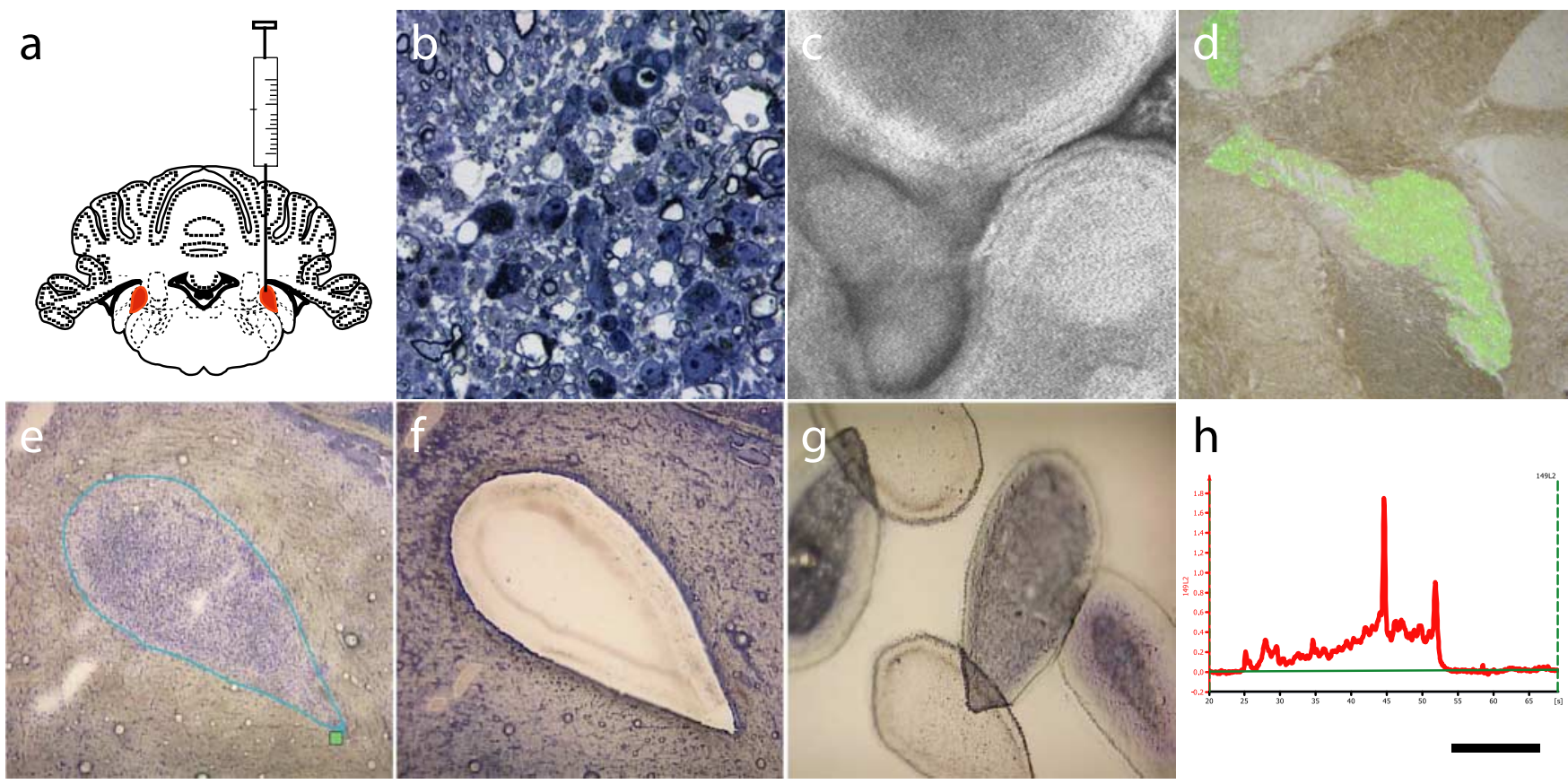

Figure 1. $\boldsymbol{a}$, Areas of focal demyelination were created by stereotactic injection of $0.01 \%$ ethidium bromide into the CCPs of young adult Sprague Dawley rats (204-242 g). $\boldsymbol{b}$, Three days later, myelin degeneration can be observed (toluidine blue-stained resin section). $c$, At this point, additional purified myelin, as confirmed by the presence of stacked membrane formations on electron micrographs of lipid droplets, was injected into the lesions. $\boldsymbol{d}$, Fluorescently labeled myelin confirmed its ability to spread evenly throughout the entire lesion. For quantitative analysis of remyelination, $30-\mu \mathrm{m}$-thick cryostat sections were thaw mounted on PEP membrane slides and stained with $0.5 \%$ toluidine blue. $\boldsymbol{e}-\boldsymbol{g}$, The lesions on eight central sections were outlined (e), cut $(\boldsymbol{f})$, and laser microdissected and captured $(\boldsymbol{g})$ into a single Eppendorf tube. $\boldsymbol{h}$, After extraction, the quality of the RNA was monitored by gel electrophoresis, and only samples of good quality were included in the subsequent analysis. Scale bar: (in $\boldsymbol{h}$ ) $\boldsymbol{a}, 4 \mathrm{~mm} ; \boldsymbol{b}, 50 \mu \mathrm{m} ; \boldsymbol{c}, 0.72 \mathrm{~nm} ; \boldsymbol{d}, 600 \mu \mathrm{m} ; \boldsymbol{e}-\boldsymbol{g}, 377 \mu \mathrm{m}$.

seen in the myelin-treated lesions resulted from arrested OPC differentiation rather than from a failure of OPC recruitment. Consistent with this hypothesis, we found that the OPC densities, measured by in situ hybridization using probes against PDGF-R $\alpha$ mRNA, a recognized marker of OPCs, were the same in both myelin- and PBS-treated lesions (Fig. 2d). The recruitment of OPCs in this lesion model is associated with their increased mRNA expression of the transcription factor Nkx2.2, an increase associated with the OPCs assuming an activated phenotype in preparation for remyelination (Fancy et al., 2004). However, the number of Nkx2.2 mRNA+ cells was significantly reduced in myelin-treated lesions compared with the PBS controls, despite the number of PDGF-R $\alpha+$ cells being similar (Fig. 2e). Moreover, the Nkx2.2+ cells were predominantly situated at the lesion perimeter. These data suggest that although the presence of myelin debris does not affect OPC recruitment, it may exert an inhibitory effect on their activation. Finally, we assessed the numbers of SR-B + macrophages in the myelin-treated and PBS control animals but found their number to be the same in the two groups (Fig. 2f).

\section{Myelin arrests OPC differentiation at a premyelinating state}

To establish the stage at which OPC differentiation was arrested, we examined lesions by electron microscopy (this approach was used rather than staining with stage-specific markers because it enabled a more accurate analysis of the relationship between the demyelinated axon and remyelinating cell). In the PBS-treated animals, nearly all of the axons within the lesion were surrounded by the thin myelin sheaths characteristic of CNS remyelination (Fig. 2g). A small proportion of the axons were remyelinated by cells with ultrastructural features of Schwann cells, as has been described previously in this lesion model (Woodruff and Frank- lin, 1999, Sim et al., 2002a). In contrast, in the myelin-treated group, remyelination was restricted to a thin rim at the edge of the lesion where the myelin was cleared (Fig. 2c). Throughout the bulk of the lesion, the axons remained demyelinated and surrounded by a dense matrix of myelin debris [identified by its typical honeycomb appearance (Graça and Blakemore, 1986)] (Fig. $2 h$ ). However, many of the demyelinated axons were contacted by oligodendrocyte processes engaged in early stages of ensheathment, but without having progressed as far as the formation of a compacted myelin sheath (Fig. $2 h, j$ ). These observations suggested that remyelination was delayed at a premyelinating stage. Interestingly, Schwann cells seemed equally vulnerable to myelin-mediated inhibition of myelin sheath formation, although they were often able to establish close contact with an axon (data not shown).

\section{Discussion}

Two observations suggest that myelin debris may be inhibitory to CNS remyelination. First, the slowing of the remyelination rate that occurs in aging animals, which is primarily attributable to a delay in OPC differentiation (Sim et al., 2002b; Woodruff et al., 2004), is associated with a poor macrophage response and delayed clearance of myelin debris (Graça and Blakemore, 1986; Shields et al., 1999; Zhao et al., 2005). Second, myelin substrates impair OPC differentiation in vitro (Robinson and Miller, 1999). In this study, we provide evidence in support of this hypothesis and identify myelin debris as a substrate present in demyelinating lesions that exerts potent inhibitory effects on the ability of adult neural precursor cells (OPCs) to generate remyelinating oligodendrocytes. A smaller, but nevertheless, significant impairment of remyelination was also induced by adding liver membrane containing the same total protein content [nonspecific mem- 

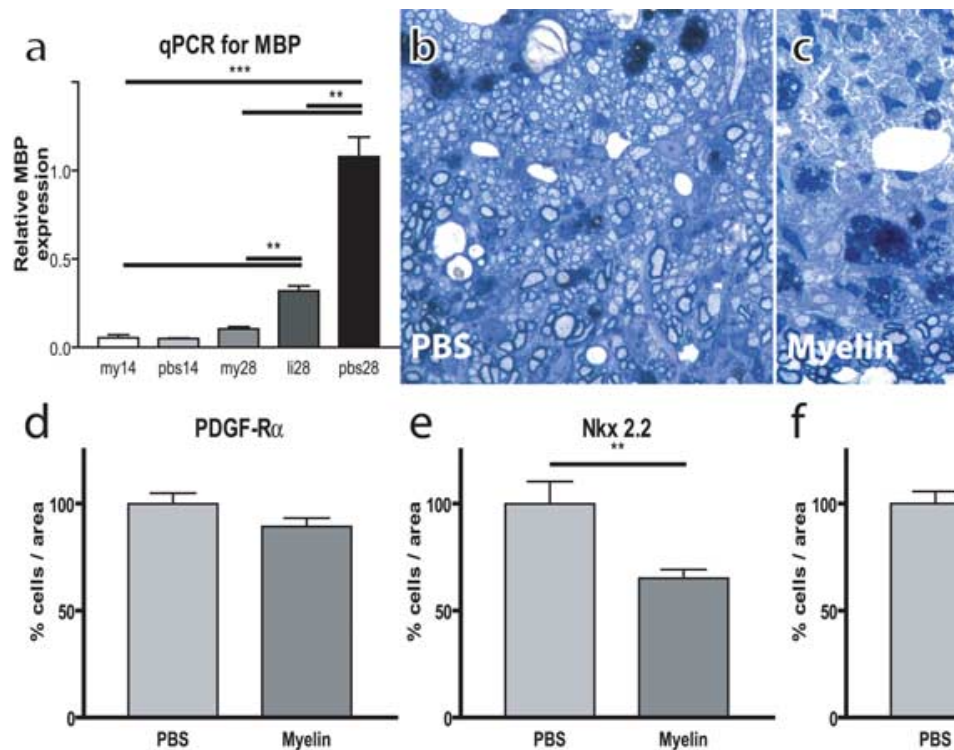

f
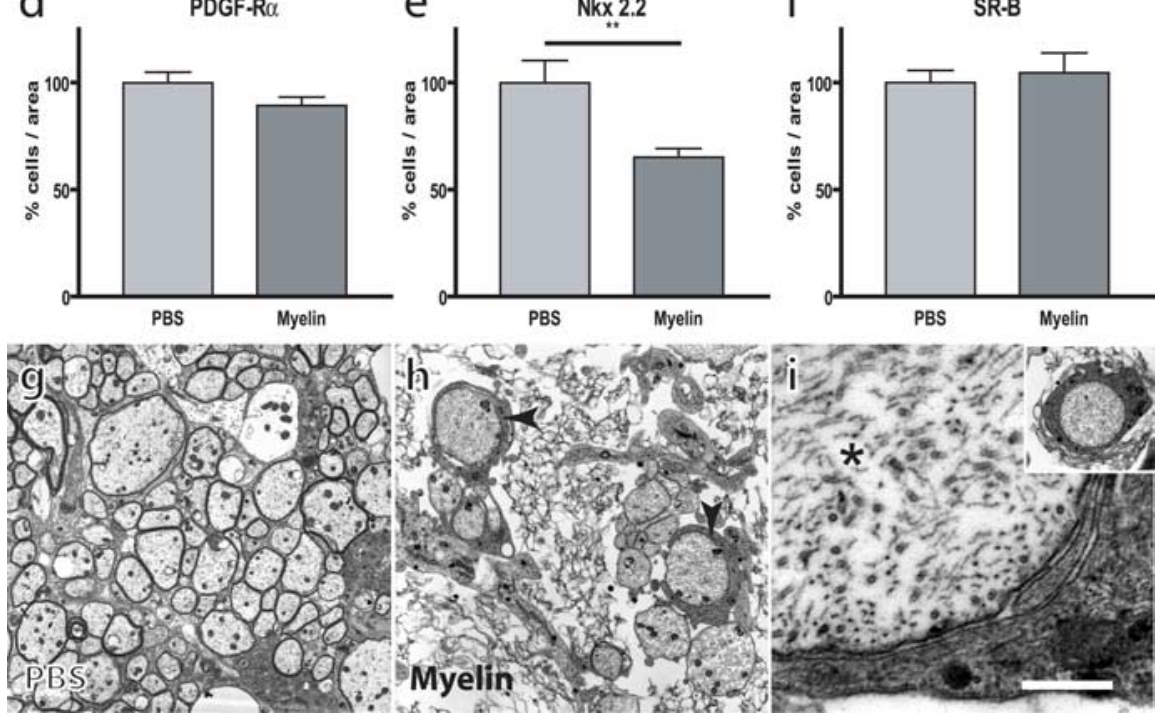

Figure 2. $\quad \boldsymbol{a}$, The extent of remyelination was quantified by qPCR for MBP relative to $\beta 2-M G$ mRNA. There was no difference in relative MBP expression at day 14 . However, at day 28, the relative MBP levels in myelin-treated animals failed to increase. Animals that received injections with equal amounts of purified liver membranes showed intermediate levels. $\boldsymbol{b}$, Light microscopy on semithin toluidine blue-stained resin sections revealed successful remyelination. There are a small number of normally myelinated axons cut in transverse section and associated with the lesion edge at the bottom of this image; the vast majority of the remaining axons are surrounded by the thin dark blue-stained myelin sheaths typical of remyelination. $\mathbf{c}$, In myelin-treated animals, remyelination was restricted to the lesion edge (bottom of image). The majority of the pale-staining axons remained demyelinated and surrounded by similarly pale-staining amorphous myelin debris (c, inset; $\boldsymbol{h}$ ). $\boldsymbol{d}, \boldsymbol{e}$, In situ hybridization for PDGF-R $\alpha$ showed comparable OPC densities (expressed as a percentage of cells in PBS controls) within lesions of myelin-treated animals and controls $8 \mathrm{~d}$ after lesion induction (d) but fewer cells expressing high levels of Nkx2.2 mRNA, a marker of OPC activation $(\boldsymbol{e}) . \boldsymbol{f}$, The densities of SR-B + macrophages was the same in myelin-treated and PBS control lesions. Electron microscopic analysis was used to establish the stage at which remyelination was arrested. $\boldsymbol{g}$, Most axons in control lesions were reinvested with myelin sheaths formed by remyelinating oligodendrocytes. $\boldsymbol{h}$, Although axons of myelin-treated animals were abundant and intact (albeit separated from one another by the presence of uncleared myelin debris), on electron micrographs they remained demyelinated. Processes (arrowheads; $\boldsymbol{h}$ ) surrounding demyelinated axons (asterisk; $\boldsymbol{i}$ ) were arrested at a premyelinating state and failed to produce compacted myelin. Scale bar: (in i) $\boldsymbol{b}, \boldsymbol{c}, 50 \mu \mathrm{m} ; \boldsymbol{g}, 0.42 \mu \mathrm{m} ; \boldsymbol{h}, 2.8 \mu \mathrm{m} ; \boldsymbol{f}, 0.28 \mu \mathrm{m}$. Error bars indicate SEM.

brane debris (Robinson and Miller, 1999)]. This may indicate that debris per se is inhibitory. However, because liver membrane does not affect the properties of OPCs in vitro (Robinson and Miller, 1999), an alternative explanation is that the excess phagocytic load provided by the liver membrane results in delayed clearance of endogenous myelin debris that persists to exert an inhibitory effect. The implication of this result is that the efficient phagocytic clearance of myelin debris generated during demyelination is a critical component of the efficiency of remyelination.

This inhibition affects primarily the stage of remyelination in which OPCs differentiate into remyelinating oligodendrocytes, because there is no impairment of the recruitment process by which new OPCs repopulate the lesion (in which they are initially destroyed) (Sim et al., 2002b). One possible explanation for our results is that myelin debris induces apoptosis of differentiating
OPCs. However, this hypothesis is not supported by in vitro data (Robinson and Miller, 1999). Moreover, ultrastructural analysis of lesions indicates that the block is occurring at late stages of maturation, because in the myelin-treated animals, there are abundant demyelinated axons ensheathed by oligodendrocyte processes without the formation of compacted myelin sheaths. By what mechanisms might myelin debris inhibit myelin sheath formation? Myelin components have been identified as prominent inhibitors of axon growth (Caroni and Schwab, 1988; Filbin, 2003), and several findings suggest that similar mechanisms may control the inhibition of OPC differentiation. Two of the important coreceptors mediating the inhibitory mechanisms of myelin components on growing axons, the neurotrophin receptor p75 ${ }^{\mathrm{NTR}}$ (Wang et al., 2002; Wong et al., 2002) as well as LINGO (Mi et al., 2004), are present on OPCs (Dowling et al., 1999; Chang et al., 2000; Petratos et al., 2004). However, especially relevant in this regard is the recent report that activation of LINGO inhibits O4+ immature oligodendrocytes from maturing into differentiated oligodendrocytes, by promoting the activity of RhoA GTPase while suppressing that of Fyn tyrosine kinase (Mi et al., 2005). In other words, LINGO-mediated signaling in oligodendrocyte lineage cells exerts a differentiation block highly reminiscent of the "ensheathment without compaction" morphology described in this study.

Our data therefore point to a unifying hypothesis in which myelin plays a central inhibitory role during the CNS regenerative processes of axon regrowth and remyelination. The present findings suggest two novel strategies that merit exploration for the promotion of myelin regeneration. First, an effective way of enhancing remyelination may consist in the stimulation of the removal of myelin debris by macrophages. Indeed, this has been implied as one of the mechanisms by which IgGs are able to enhance remyelination (Warrington et al., 2001). Second, an understanding of the molecular processes involved may provide possibilities to modulate and overcome inhibition of OPC differentiation mediated by myelin.

\section{References}

Arnett HA, Fancy SP, Alberta JA, Zhao C, Plant SR, Kaing S, Raine CS, Rowitch DH, Franklin RJM, Stiles CD (2004) bHLH transcription factor Olig1 is required to repair demyelinated lesions in the CNS. Science 306:2111-2115.

Caroni P, Schwab ME (1988) Antibody against myelin-associated inhibitor of neurite growth neutralizes nonpermissive substrate properties of CNS white matter. Neuron 1:85-96.

Chang A, Nishiyama A, Peterson J, Prineas J, Trapp BD (2000) NG2- 
positive oligodendrocyte progenitor cells in adult human brain and multiple sclerosis lesions. J Neurosci 20:6404-6412.

Chang A, Tourtellotte WW, Rudick R, Trapp BD (2002) Premyelinating oligodendrocytes in chronic lesions of multiple sclerosis. N Engl J Med 346:165-173.

Dowling P, Ming X, Raval S, Husar W, Casaccia-Bonnefil P, Chao M, Cook S, Blumberg B (1999) Up-regulated p75NTR neurotrophin receptor on glial cells in MS plaques. Neurology 53:1676-1682.

Fancy SPJ, Zhao C, Franklin RJM (2004) Increased expression of Nkx2.2 and Olig2 identifies reactive oligodendrocyte progenitor cells responding to demyelination in the adult CNS. Mol Cell Neurosci 27:247-254.

Filbin MT (2003) Myelin-associated inhibitors of axonal regeneration in the adult mammalian CNS. Nat Rev Neurosci 4:703-713.

Franklin RJM (2002) Why does remyelination fail in multiple sclerosis? Nat Rev Neurosci 3:705-714.

Fruttiger M, Karlsson L, Hall AC, Abramsson A, Calver AR, Bostrom H, Willetts K, Bertold CH, Heath JK, Betsholtz C, Richardson WD (1999) Defective oligodendrocyte development and severe hypomyelination in PDGF-A knockout mice. Development 126:457-467.

Graça DL, Blakemore WF (1986) Delayed remyelination in rat spinal cord following ethidium bromide injection. Neuropathol Appl Neurobiol 12:593-605.

Horner PJ, Power AE, Kempermann G, Kuhn HG, Palmer TD, Winkler J, Thal LJ, Gage FH (2000) Proliferation and differentiation of progenitor cells throughout the intact adult rat spinal cord. J Neurosci 20:2218-2228.

Kotter MR, Zhao C, Van Rooijen N, Franklin RJM (2005) Macrophagedepletion induced impairment of experimental CNS remyelination is associated with a reduced oligodendrocyte progenitor cell response and altered growth factor expression. Neurobiol Dis 18:166-175.

Mi S, Lee X, Shao Z, Thill G, Ji B, Relton J, Levesque M, Allaire N, Perrin S, Sands B, Crowell T, Cate RL, McCoy JM, Pepinsky RB (2004) LINGO-1 is a component of the Nogo-66 receptor/p75 signaling complex. Nat Neurosci 7:221-228.

Mi S, Miller RH, Lee X, Scott ML, Shulag-Morskaya S, Shao Z, Chang J, Thill G, Levesque M, Zhang M, Hession C, Sah D, Trapp B, He Z, Jung V, McCoy JM, Pepinsky RB (2005) LINGO-1 negatively regulates myelination by oligodendrocytes. Nat Neurosci 8:745-751.

Norton WT, Poduslo SE (1973) Myelination in rat brain: method of myelin isolation. J Neurochem 21:749-757.

Petratos S, Gonzales MF, Azari MF, Marriott M, Minichiello RA, Shipham KA, Profyris C, Nicolaou A, Boyle K, Cheema SS, Kilpatrick TJ (2004) Expression of the low-affinity neurotrophin receptor, p75(NTR), is upregulated by oligodendroglial progenitors adjacent to the subventricular zone in response to demyelination. Glia 48:64-75.
Prineas JW, Connell F (1979) Remyelination in multiple sclerosis. Ann Neurol 5:22-31.

Robinson S, Miller RH (1999) Contact with central nervous system myelin inhibits oligodendrocyte progenitor maturation. Dev Biol 216:359-368.

Shields SA, Gilson JM, Blakemore WF, Franklin RJM (1999) Remyelination occurs as extensively but more slowly in old rats compared to young rats following gliotoxin-induced CNS demyelination. Glia 28:77-83.

Sim FJ, Hinks GL, Franklin RJM (2000) The re-expression of the homeodomain transcription factor Gtx during remyelination of experimentally induced demyelinating lesions in young and old rat brain. Neuroscience 100:131-139.

Sim FJ, Zhao C, Li WW, Lakatos A, Franklin RJM (2002a) Expression of the POU-domain transcription factors SCIP/Oct-6 and Brn-2 is associated with Schwann cell but not oligodendrocyte remyelination of the CNS. Mol Cell Neurosci 20:669-682.

Sim FJ, Zhao C, Penderis J, Franklin RJM (2002b) The age-related decrease in CNS remyelination efficiency is attributable to an impairment of both oligodendrocyte progenitor recruitment and differentiation. J Neurosci 22:2451-2459.

Wang KC, Kim JA, Sivasankaran R, Segal R, He Z (2002) p75 interacts with the Nogo receptor as a co-receptor for Nogo, MAG and OMgp. Nature 420:74-78.

Warrington AE, Bieber AJ, Ciric B, Van K, V, Pease LR, Mitsunaga Y, Paz Soldan MM, Rodriguez M (2001) Immunoglobulin-mediated CNS repair. J Allergy Clin Immunol 108:S121-S125.

Wolswijk G (1998) Chronic stage multiple sclerosis lesions contain a relatively quiescent population of oligodendrocyte precursor cells. J Neurosci 18:601-609.

Wong ST, Henley JR, Kanning KC, Huang KH, Bothwell M, Poo MM (2002) A p75(NTR) and Nogo receptor complex mediates repulsive signaling by myelin-associated glycoprotein. Nat Neurosci 5:1302-1308.

Woodruff RA, Fruttiger M, Richardson WD, Franklin RJM (2004) Plateletderived growth factor regulates oligodendrocyte progenitor numbers in adult CNS and their response following CNS demyelination. Mol Cell Neurosci 25:252-262.

Woodruff RH, Franklin RJM (1999) Demyelination and remyelination of the caudal cerebellar peduncle of adult rats following stereotaxic injections of lysolecithin, ethidium bromide, and complement/anti-galactocerebroside: a comparative study. Glia 25:216-228.

Zhao C, Li WW, Franklin RJM (2005) Differences in the early inflammatory responses to toxin-induced demyelination are associated with the agerelated decline in CNS remyelination. Neurobiol Aging, in press. 